\title{
The Tale of Two C's, Cancer and COVID-19: Oncologist's Viewpoint from India
}

\author{
Dharma Ram Poonia ${ }^{1}$, Amit Sehrawat ${ }^{2}$, Manoj Gupta ${ }^{3}$
}

${ }^{1}$ Department of Surgical Oncology, All India Institute of Medical Sciences, Rishikesh, India. ${ }^{2}$ Department of Medical Oncology Haematology, All India Institute of Medical Sciences, Rishikesh, India. ${ }^{3}$ Department of Radiation Oncology, All India Institute of Medical Sciences, Rishikesh, India.

\begin{abstract}
Cancer as a malady is perspicacious and molds itself just before we reach to stab it, on the other hand, COVID-19, an entity with limited genetic material is affecting entire humanity in such a florid way is overwhelming and the mechanism is so simple yet so authoritative. COVID-19 pandemic is affecting all dimensions of mankind with maximum impact on the healthcare system and economy. We the oncologists are so constrained and helpless due to a blooming pandemic, which we have never seen in recent history. We wish to highlight certain issues pertaining to cancer care, which became relevant in such vacillating anticipation. Another dimension needs consideration for limited resources countries; they will always be in the state of prolonged waitlists, limited availability of quality care centers, and hence inferior cancer outcome. Closing the machinery of radiotherapy, surgical and medical oncologists sitting idle is a big loss for sure. We here discuss and suggest a few need of the hour interventions.
\end{abstract}

Keywords: COVID-19- Cancer care- India

Asian Pac J Cancer Care, 5 (Suppl 1), 143-146

\section{Introduction}

Cancer as a malady is perspicacious and molds itself just before we reach to stab it. Such excellent harmony amongst cells and their microenvironment is beautiful to witness, yet annoying for a clinician and scientist. On the other hand, COVID-19, an entity with limited genetic material (ss, + sense RNA 26-32kb) can affect entire humanity in such a florid way is overwhelming and the mechanism is so simple yet so authoritative [1]. The difference here is that probably we could have prevented such zoonotic infections killing humans, but that is not always possible with cancer. However, cancer is known since antiquity but remains an indecipherable entity because it has complex pathogenesis, requires complex treatment and shows a complex outcome. These patients are a unique set of population, needs specialized, multimodality and prolonged control care.

Coronavirus discovered in 1965 (Strain B814) responsible for the insipid common cold to humans and kept the reputation of submissive human pathogen until 2002, when SARS-CoV presented as pandemic, responsible
Submission Date: 05/23/2020Ａcceptance Date: 06/28/2020 for nearly 8000 infections and 800 deaths across 29 countries and responsible strain was animal pathogen, which evolve capabilities for human transmission by loco regional gastronomy and culture. India had reported three such cases but no death. Another Epidemic of MERS$\mathrm{CoV}$ (Middle East respiratory syndrome; Camel Flu) is worth mentioning, it started in 2012 and continuing in low frequency, with nearly 2500 cases and 866 deaths across the globe. Most recently in line is the COVID-19 pandemic, which started in December 2019 in Wuhan city of China, attributed to SARS-CoV 2.0. This is more florid than two earlier events and declared as a pandemic in March 2020 by WHO, as of now, more than 190 countries have reported more 3.5 million confirmed cases with about 2.5 lakh deaths by 7 May 2020. This reinforces the fact that yet again, we are far from perfect [2].

\section{India's Response}

COVID-19 pandemic is affecting all dimensions of mankind with maximum impact on the healthcare system

Corresponding Author:

Dr. Amit Sehrawat

Department of Medical Oncology Haematology, All India Institute of Medical Sciences, Rishikesh, India.

Email: dramitsehrawat@gmail.com, amit.monc@aiimsrishikesh.edu.in 
and economy. In response to the COVID-19 pandemic, the Government of India acted and imposed complete lock down for 7 weeks from 25 March 2020, which later modified as selective lockdown, to check the rambunctious expansion, and proven fairly successful. The Ministry of Health and Family welfare rose to the occasion and ensured prompt capacity building, training for health care and collaborating with the public and private sector. Indian Council of Medical Research advised COVID-19 testing for all symptomatic individuals returning from international travel in preceding 2 weeks, all symptomatic exposed health care workers and asymptomatic individual having a history of close contact with a confirmed case [3]. Currently, 132 public and 52 private centres are offering COVID-19 testing using RT-PCR on the throat and nasal swab. Board of Governors Medical Council of India issued telemedicine guidelines to facilitate and maintain patient care amid this pandemic. Online teaching for nurses and doctors using online video platforms is being practiced and promoted [3].

\section{Oncologist's trepidation}

We the oncologists are so constrained and helpless due to a blooming pandemic. We wish to highlight certain issues pertaining to cancer care, which became relevant in such vacillating anticipation. Recent publications from China with small size, retrospective experiences, have reported the impact of COVID-19 on cancer. But susceptibility for mortality associated with COVID-19 for cancer patients, beyond age and other comorbidities is not well established yet. University of Wuhan Hospital study concluded that cancer patients are twice at the risk of getting affected with COVID-19. Liang et al. reported the rate of hospital-acquired COVID-19 was up to $41 \%$ in, while it was reported to be $28.6 \%$ in specialized cancer hospitals by $\mathrm{Yu} \mathrm{J}$ et al. Among the COVID-19 cancer cohort, $35 \%$ were advanced cancers, $70 \%$ of those had a fulminant course. Rate of COVID-19 infection in cancer patients was higher than community level (OR, 2.31; 95\% CI, 1.89-3.02), but that is due to higher admission and hospital stay in those patients [4-5]. COVID-19 has a contagion metric (R0) of $2-2.5$, but natural history yet to be deciphered. The first case in India was reported on 30 January 2020, and cases are increasing gradually, despite mitigation efforts and lockdown. As per current predictions, we expect it will remain for the next 3 to 4 months. So, it is not going to settle soon hence health care providers must learn to work with raincoats in corona rain [6].

Data on Cancer's contribution to total OPD and IPD patient load in India is not clear but it is substantial and requires significant infrastructure $\&$ man-hours of health care workers. As per WHO reports, cancer is responsible for about six percent of total deaths in India, which is lesser than global data of $13 \%$ [7]. 70\% of global cancer deaths are reported from low middle-income countries (LMIC). Any cancer patient eligible for curative-intent treatment is quasi-emergency and expectant management is detrimental for most of the cancers. Delaying cancer treatment for more than one month adversely affects the survival across all stages [8]. How much time one can wait safely is not possible/ethical to find, we cannot generate literature on that. The desirable time to initiate cancer treatment is not based on evidence but logistics. As per NHS, cancer treatment should be started within 62 days of diagnosis. In India, we do not have such guidelines. If a patient has an acute cardiac event or stroke needs it mandates urgent medical care and lockdown is providing relaxation for that. Patients requiring elective surgery like joint replacement can wait and need not much attention during a pandemic. There are two questions, whether we can give the treatment breaks to these patients and can we offer them something alternative if we accept the break?

An oncologist considers the stage of the disease, cancer biology, performance status, comorbidities, etc. in addition to logistics before designing treatment. Logistics includes the availability of safe, effective, and prompt treatment. Logistics have the highest impact on the outcome though least studied aspect. Patients in early-stage conditions need to be dealt with differently as they are potentially curable. For advanced disease, despite prompt and effective treatment, they might not benefit a lot. There are different guidelines, based on COVID-19 burden, government policies on restriction, epidemiological factors, and availability of resources in addition to cancer and patient-related factors. Access to healthcare for cancer patients is difficult in the current restrictive mobilization state, as public transportation is seized and travel for such patients is a major issue.

\section{Precision medicine in COVID-19 Storm}

The alternative for such unplanned gap cannot be explored with strong study designs. For hormone-positive breast, hormonal therapy is probably the most effective option for stages of the disease, but such alternative options are missing for many clinical scenarios. Alternative oral drugs like Capecitabine, Cyclophosphamide, or Etoposide are options but inferior choices. Balancing this is a cumbersome task. Another dimension needs consideration for limited resources countries; they will always be in the state of prolonged waitlists, limited availability of quality care centers, and hence inferior cancer outcome. Closing the machinery of radiotherapy, surgical and medical oncologists sitting idle is a big loss for sure. A country with more than seven lakh, annual death due to cancer cannot afford to waste limited resources. Moreover, it is frightening to imagine the struggling health care, if we postpone everything for later. We are proposing our essential recommendation based on local needs, some specific and some-general (Table 1).

\section{Declaration and authorship}

\section{Contributions of authors}

DRP and AS conceived the research idea and searched the literature.

AS ensured data collection, analysis and interpretation. Manuscript written by DRP and AS.

Manuscript and facts were reviewed by MKG. 
Table 1. Precision Medicine in COVID-19 Storm

\begin{tabular}{|c|c|}
\hline Domains & Recommendations \\
\hline \multirow[t]{4}{*}{ Administration } & $\begin{array}{l}\text { - Working hours: Identify the burnout of HCWs, keep them motivated, and appraise them regularly about evolving } \\
\text { scenarios and road ahead. }\end{array}$ \\
\hline & $\begin{array}{l}\text { - Psychological Support: Strategies to uplift the morale HCWs are vital in this battle, so the development of a } \\
\text { psychological support team is indispensable. }\end{array}$ \\
\hline & $\begin{array}{l}\text { - Detached, discrete \& distinct cancer care: Separate wing/area for cancer care, away from COVID-19 care with } \\
\text { well-planned protocols for screening and dedicated quarantine policies for Cancer patients. }\end{array}$ \\
\hline & $\begin{array}{l}\text { - Allied specialty: Cancer provider from allied specialty (Pathology/radiology/dietetics/anesthetist) needs to be identified } \\
\text { and dedicated to cancer care only. }\end{array}$ \\
\hline \multirow[t]{3}{*}{ Human Resources } & $\begin{array}{l}\text { - Their protection with appropriate training, equipment availability, PPEs, timely work segregation, and quarantine are } \\
\text { the key steps. }\end{array}$ \\
\hline & - They need to be work in planned teams specific for oncology subspecialties for a defined period. \\
\hline & - They can switch their roles periodically to maintain a continuum of care for cancer patients. \\
\hline \multirow[t]{4}{*}{ Non-Human Resource } & - Blood products, neutropenic isolation rooms, and PPEs need to be allocated with almost care. \\
\hline & - All Cancer care units need to be ready with a contingency plan according to their local resources and needs. \\
\hline & $\begin{array}{l}\text { - Approach for drafting workflows and policies shall be adaptable for local needs and day-to-day evolving scenarios, } \\
\text { which is critically important for pandemics management planning. }\end{array}$ \\
\hline & $\begin{array}{l}\text { - PPEs and Masks strategy to be devised specifically to a clinical setting. Routine cancer care to be provided using a } \\
\text { surgical mask and meticulous hand hygiene and N-95 respirators/PPEs to be reserved only for COVID-19 areas or } \\
\text { neutropenic units of oncology. }\end{array}$ \\
\hline \multirow[t]{5}{*}{ General Mitigation Policies } & $\begin{array}{l}\text { - Social distancing, avoiding unnecessary travel and limiting crowding is most crucial for fighting COVID-19 or any other } \\
\text { similar pandemics }\end{array}$ \\
\hline & - Both OPD, as well as IPD visits, need to be curtailed with only one care provider permitted with the patient. \\
\hline & - Routine follow-up visits to be suspended for the next 8-12 weeks. \\
\hline & $\begin{array}{l}\text { - Administrative staff needs to be sensitive and motivated enough to identify the burnout of HCWs, keep them motivated, } \\
\text { appraise them regularly about evolving scenario and road ahead. Strategies to uplift the morale of HCWs are vital in this } \\
\text { battle. }\end{array}$ \\
\hline & - No Group meetings to be allowed \\
\hline \multirow[t]{7}{*}{ Patients care } & - Information for patients: National wide awareness for each individual and potential harms should be readily available. \\
\hline & $\begin{array}{l}\text { - Personalized care: Every Cancer patient is having a unique clinical situation and requires evaluation on a case-to-case } \\
\text { basis with the participation of all stakeholders including care providers, allaying their concerns about consequences of } \\
\text { continuing or interrupting the cancer-directed therapy. }\end{array}$ \\
\hline & $\begin{array}{l}\text { - New Patients: Timely labeling the intent of treatment (Curative or palliative), curative patients should be offered care } \\
\text { promptly. Palliative patients with acute emergency provide prompt care. }\end{array}$ \\
\hline & - Potentially curable patients with indolent disease biology- can wait with appropriate counseling. \\
\hline & $\begin{array}{l}\text { - Adjuvant Care: care should not be delayed. The treating physician shall identify, the best action plan for the patient } \\
\text { individually and ensure delivery. Telemedicine, video consultations and advice to second-tier centers should be } \\
\text { encouraged. }\end{array}$ \\
\hline & $\begin{array}{l}\text { - Palliative treatments beyond first-line with limited impact on cancer outcomes can be delayed, this will also reduce the } \\
\text { burden on health care system with limited resources like India. }\end{array}$ \\
\hline & $\begin{array}{l}\text { - Maintenance chemotherapy patients can also be put on a lower priority list and such treatments can be discontinued with } \\
\text { informed decision-making process. }\end{array}$ \\
\hline \multirow[t]{3}{*}{ Training \& capacity building } & $\begin{array}{l}\text { - Use of appropriate technology can prove very important. Services like telemedicine, videoconferencing, WhatsApp, } \\
\text { email and telephonic consultations will reduce unnecessary exposure events while maintaining basic care for the needy. }\end{array}$ \\
\hline & $\begin{array}{l}\text { - Separate OPD for cancer patients after COVID-19 screening (Fever/Cough/Breathing difficulty with History of } \\
\text { exposure) and timely disposal. }\end{array}$ \\
\hline & $\begin{array}{l}\text { - Segregation of entry of HCWs and patients' health care facilities to be planned to further strengthen social distancing an } \\
\text { avoiding unintended exposure. }\end{array}$ \\
\hline \multirow[t]{3}{*}{ Collaboration \& Research } & - Cancer corona consortium reporting for cases. \\
\hline & - Cancer research should be continued, without break. \\
\hline & - COVID-19 research is promoted by Govt. of India, shall be encouraged and appreciated. \\
\hline \multirow[t]{4}{*}{ Teaching } & - Involvement of Medical and Nursng graduates for capacity building and training to do basic supportive or clinical work \\
\hline & - Classical methods of teaching and lectures to be suspended \\
\hline & - Teleconferencing for academic classes or COVID-19 training to be promoted \\
\hline & - Practical training must strictly follow the rules of social distancing \\
\hline Future & - Focus on continuous capacity building for any such eventualities in the future and draft effective policy. \\
\hline
\end{tabular}


Conflict of Interest

Authors declare no conflict of interest

Financial support

No financial support taken for this manuscript

\section{References}

1. Lu R, Zhao X, Li J, Niu P, Yang B, Wu H, Wang W, Song H, Huang B, Zhu N, Bi Y, Ma X, Zhan F, Wang L, Hu T, Zhou H, Hu Z, Zhou W, Zhao L, Chen J, Meng Y, Wang J, Lin Y, Yuan J, Xie Z, Ma J, Liu WJ, Wang D, Xu W, Holmes EC, Gao GF, Wu G, Chen W, Shi W, Tan W. Genomic characterisation and epidemiology of 2019 novel coronavirus: implications for virus origins and receptor binding. The Lancet. 2020 02;395(10224):565-574. https://doi.org/10.1016/s01406736(20)30251-8.

2. Novel Coronavirus (2019-nCoV) situation reports [Internet]. Who.int. 2020 [cited 2 April 2020]. Available from: https://www.who.int/emergencies/diseases/novelcoronavirus-2019/situation-reports.

3. COVID-19 | Indian Council of Medical Research | Government of India [Internet]. Icmr.nic.in. 2020 [cited 4 April 2020]. Available from: https://icmr.nic.in/content/covid-19..

4. Liang W, Guan W, Chen R, Wang W, Li J, Xu K, Li C, Ai Q, Lu W, Liang H, Li S, He J. Cancer patients in SARSCoV-2 infection: a nationwide analysis in China. The Lancet Oncology. 2020 03;21(3):335-337. https://doi.org/10.1016/ s1470-2045(20)30096-6

5. Yu J, Ouyang W, Chua MLK, Xie C. SARS-CoV-2 Transmission in Patients With Cancer at a Tertiary Care Hospital in Wuhan, China. JAMA Oncology. 202003 25;. https://doi.org/10.1001/jamaoncol.2020.0980

6. Shankar A, Saini D, Roy S, Mosavi Jarrahi A, Chakraborty A, Bharti SJ, Taghizadeh-Hesary F. Cancer Care Delivery Challenges Amidst Coronavirus Disease - 19 (COVID-19) Outbreak: Specific Precautions for Cancer Patients and Cancer Care Providers to Prevent Spread. Asian Pacific Journal of Cancer Prevention. 202003 01;21(3):569-573. https://doi.org/10.31557/apjcp.2020.21.3.569

7. Neal RD, Tharmanathan P, France B, Din NU, Cotton S, Fallon-Ferguson J, Hamilton W, Hendry A, Hendry M, Lewis R, Macleod U, Mitchell ED, Pickett M, Rai T, Shaw K, Stuart N, Tørring ML, Wilkinson C, Williams B, Williams $\mathrm{N}$, Emery J. Is increased time to diagnosis and treatment in symptomatic cancer associated with poorer outcomes? Systematic review. British Journal of Cancer. 2015 03;112(S1):S92-S107. https://doi.org/10.1038/bjc.2015.48

8. Murthy S, Gomersall CD, Fowler RA. Care for Critically Ill Patients With COVID-19. JAMA. 202004 21;323(15):1499. https://doi.org/10.1001/jama.2020.3633

\section{(ब) $\odot \otimes$}

This work is licensed under a Creative Commons AttributionNon Commercial 4.0 International License. 